\title{
Beta-glucan attenuates cerebral ischemia/reperfusion-induced neuronal injury in a C57BL/J6 mouse model
}

\author{
Kürşat Kaya ${ }^{\circledR 1^{*}}$, Osman Çiftçi², Mustafa Namık Öztanır³, Elif Taşlıdere ${ }^{4}$, Neşe Başak Türkmen ${ }^{5}$
}

${ }^{1}$ Department of Biochemistry, Faculty of Pharmacy, Adiyaman University, Adiyaman, Turkey, ${ }^{2}$ Department of Medical Pharmacology, Faculty of Medicine, Pamukkale University, Denizli, Turkey, ${ }^{3}$ Department of Brain and Neurosurgery, Faculty of Medicine, Inonu University, Malatya, Turkey, ${ }^{4}$ Department of Histology and Embryology, Faculty of Medicine, Bezmialem Vakif University, Istanbul, Turkey, ${ }^{5}$ Department of Pharmaceutical Toxicology, Faculty of Pharmacy, Inonu University, Malatya, Turkey

\begin{abstract}
Beta-glucans $(\beta \mathrm{g})$, that have many useful effects on human health, are natural polysaccharides. Our aim in this study was to determine useful effect of $\beta \mathrm{g}$ against oxidative and neuronal damage caused by global cerebral ischemia/reperfusion (IR) in stroke imitated mice via surgical operation. A total of 40 mice divided into four equal groups randomly. The group 1 (sham operated) was kept as control. Bilateral carotid arteries of subjects in group $2(\mathrm{I} / \mathrm{R})$ and group $4(\mathrm{I} / \mathrm{R}+\beta \mathrm{g})$ were clipped for $15 \mathrm{~min}$, and the mice in group $4(\mathrm{I} / \mathrm{R}+\beta \mathrm{g})$ were treated with $\beta \mathrm{g}(50 \mathrm{mg} / \mathrm{kg} /$ day $)$, while the mice in group $2(\mathrm{I} / \mathrm{R})$ were treated with only vehicle for 10 days. The mice of group $3(\beta \mathrm{g})$ were treated with $\beta \mathrm{g}$ for 10 days without carotid occlusion. Global cerebral I/R significantly increased oxidative stress and decreased members of antioxidant defense system. In addition, I/R caused histopathological damage in the brain tissue. However, $\beta \mathrm{g}$ treatment ameliorated both oxidative and histopathological effects of I/R. Our present study showed that $\beta \mathrm{g}$ treatment significantly ameliorated oxidative and histological damage in the brain tissue caused by cerebral I/R. Therefore, $\beta \mathrm{g}$ treatment can be used as supportive care for ischemic stroke patients.
\end{abstract}

Keywords: Global cerebral I/R. Oxidative stress. Neuronal damage. Beta-glucan. C57BL/J6 mice.

\section{INTRODUCTION}

The continuation of normal brain function depends on the provision of sufficient oxygen and glucose to the brain through blood flow, and a reduction or block in the brain blood flow can cause fatal brain damage (Ciftci, Oztanir, Cetin, 2014). A severe reduction or block in the brain blood flow occurs in several situations, such as cerebral ischemia, cardiac arrest, and cardiovascular surgery (Park et al., 2016). Stroke is one of the most prevalent causes of death, adult long-term disability, and dementia, and approximately $80 \%$ of all stroke cases are ischemic stroke (Zhao et al., 2017). After cerebral ischemia, restoration of perfusion to the ischemic area begins a cascade, causing secondary neuronal damage (Alawieh, Elvington, Tomlinson, 2015). Reperfusion causes an additional injury called ischemia/reperfusion

\footnotetext{
*Correspondence: K. Kaya. Department of Biochemistry, Faculty of Pharmacy, Adiyaman University, Adiyaman, Turkey, Altinşehir Mah. 3005. Sok. No: 13, 02040. Tel: +90 41622338 00/3058 / Fax: +90 (416) 223 3807. E-mail: kkaya@adiyaman.edu.tr
}

(I/R) injury in the ischemic area. The $I / R$ injury is responsible for cerebral microcirculatory disturbances, such as reactive oxygen species (ROS) outburst, inflammatory mediator overproduction, and leukocyte infiltration (Sun, Fan, Han, 2015). In fact, the pathological process of ischemic stroke has not been completely elucidated yet, but the responsibility of oxidative damage caused by ROS stands out in this process (Oztanir et al., 2014a). Therefore, the ameliorating effects of natural antioxidants against brain damage caused by I/R have been extensively studied (Lalkovičová, Danielisová, 2016). Hesperidin (Oztanir et al., 2014a), 18ß-Glycyrrhetinic acid (Oztanir et al., 2014b), and $\beta$-myrcene (Ciftci, Oztanir, Cetin, 2014) are some of the antioxidants shown to have beneficial effects against brain damage caused by I/R. However, to the best of our knowledge, beta-glucan $(\beta \mathrm{g})$ was not tested on I/R-induced brain damage until now.

$\beta \mathrm{gs}$ are natural polysaccharides derived from many mushrooms, fungi, and cereal species, and they have many pharmacological effects, such as immunomodulation, antioxidant, free radical scavenging, 
antibacterial, antifungal, antitumoral, antilipid, antitoxic, and radioprotective activity (Gulmen et al., 2010; Kaya et al., 2016). The beneficial effects of $\beta g s$ against brain damage induced by various causes have been shown in many previous studies (Alp et al., 2012; Kaya et al., 2016; Selli et al., 2015). For example, $\beta \mathrm{g}$ ameliorated both oxidative and histologic brain damage caused by cisplatin, a chemotherapeutic agent (Kaya et al., 2016). In addition, some previous studies showed that $\beta g$ s have useful effects against damage to many organs other than the brain (Bolcal et al., 2007; Gulmen et al., 2010). In this context, the present study aimed to investigate the potential beneficial effect of $\beta g$ against brain damage caused by I/R. For this purpose, the effect of $\beta g$ on I/Rinduced brain damage was evaluated biochemically and histologically.

\section{MATERIAL AND METHODS}

\section{Chemicals}

$\beta \mathrm{g}$ was purchased from a pharmacy as IMUNEKS (Mustafa Nevzat Drug Industry, İst, Turkey) in capsule form. Each capsule contains $50 \mathrm{mg}$ of $\beta \mathrm{g}$ obtained from bread yeast. All other chemicals were purchased from Sigma Chemical Co. (St. Louis, MO) and were either analytical grade or the highest grade available.

\section{Animals and experimental protocol}

The current study was approved by the Ethical Committee on Animal Research of Inonu University (Date: 27/07/2015 and Protocol No: 2015/A-55) and performed appropriately according to the Guidelines for Animal Research of the National Institutes of Health (NIH). C57BL/6J male mice (clean grade) were provided from Inonu University Laboratory Animals Research Center (Malatya, Turkey). The mice weighing 18-22 g were accommodated in sterilized polypropylene cages and were nourished with standard commercial food pellets and water ad libitum. All mice were held under standard environmental conditions (12-h light/dark cycle, $21 \pm 2{ }^{\circ} \mathrm{C}$ ambient temperatures, and $60 \pm 5 \%$ humidity). In total, 40 mice were randomly partitioned into four groups $(\mathrm{n}=10)$, and the groups were named group 1 (sham-operated $[\mathrm{SH}]$ ), group 2 (global cerebral I/R), group $3(\beta g)$, and group $4(\beta g+I / R)$. Mice in the $\mathrm{SH}$ and $\mathrm{I} / \mathrm{R}$ groups were given only an isotonic saline solution for 10 days orally by gavage. In the $\beta g$ and $\beta g+I / R$ groups, mice were treated with $\beta \mathrm{g}(50 \mathrm{mg} / \mathrm{kg} /$ day) orally for 10 days following the I/R procedure. At the end of
10 days, all mice were euthanized under ether anesthesia, and tissue samples were taken for biochemical analyses and histological examination.

\section{Surgical procedure}

For the purpose of creating global cerebral ischemia, the method of Yonekura et al. (2004) was used. The mice were anesthetized with xylazine $(5 \mathrm{mg} / \mathrm{kg}$, intraperitoneal [i.p.]) and ketamine (100 mg/kg, i.p.), and then the cervical midlines of the mice were incised. The bilateral common carotid arteries of the mice in the I/R and $\beta g+I / R$ groups were separated and blocked simultaneously for $10 \mathrm{~min}$ using two vascular miniclips. The surgical procedure was repeated for mice in the $\mathrm{SH}$ and $\beta \mathrm{g}$ groups likewise, but their carotid arteries were not clipped. After the operation, all mice were kept in a thermal room to wake up from anesthesia.

\section{Biochemical analyses}

The brain tissue was homogenized as explained previously (Kaya et al., 2016). Spectrophotometric methods were used to determine the levels of thiobarbituric acid reactive substances (TBARS) and total glutathione (GSH), along with the activities of catalase (CAT), CuZnsuperoxide dismutase (SOD), and glutathione peroxidase (GPx). The TBARS level, an index for lipid peroxidation, was determined according to the method of Yagi (1998). SOD, CAT, GPx, and GSH are members of antioxidant defense systems that protect against oxidative damage (Kaya et al., 2016). The GSH level was measured using the method of Sedlak and Lindsay (1968) and expressed as $\mathrm{nmol} / \mathrm{ml}$. SOD activity was determined according to the method of Sun, Oberley, and $\mathrm{Li}$ (1988). In this method, the amount of protein that reduces the nitro blue tetrazolium reduction rate by $50 \%$ expresses one unit of SOD activity. CAT activity was evaluated using the method described by Aebi et al. (1974). The decrease in absorbance caused by the enzymatic decomposition of peroxide was measured at $220 \mathrm{~nm}$. The difference in absorbance per unit time was considered a measure of CAT enzyme activity. GPx was measured according to the method of Paglia and Valentina (1967). GPx activity was expressed as IU/mg protein.

\section{Histological assessment}

Brain samples were fixed in 10\% formalin and were embedded in paraffin. Tissue sections $5 \mu \mathrm{m}$ in thickness were mounted on slides and stained with hematoxylin and eosin (H\&E) for general cerebral structure. The severity of 
the damage to the cerebral cortex was semi-quantitatively assessed according to the following: inflammatory cell infiltration, congestion, and eosinophilic degeneration of pyramidal cells.

Microscopic damage was identified as: (0) absent, (1) slight $(0-<20 \%$ cerebral cortex injury, (2) moderate (21-50\% cerebral cortex injury), and (3) severe (50-100\% cerebral cortex injury) for each criterion. The sections were examined by a Leica DFC 280 light microscope by a histologist unaware of the status of the animals.

\section{Statistical analysis}

All statistical analyses were performed using the SPSS 13.0 computer program (SPSS Inc., Chicago, IL, USA). For the statistical analyses of biochemical values, one-way analysis of variance (ANOVA) and post-hoc Tukey's honestly significant differences test were used, and the degree of significance was designated as $p \leq 0.01$.

\section{RESULTS}

\section{Biochemical results}

The TBARS, GSH, CAT, GPx, and SOD levels in mice brain tissue are given in Table I. The results indicated that global cerebral I/R (I/R group) induced a significant increase in the TBARS level and a significant decrease in the GSH, CAT, GPx, and SOD levels compared with the $\mathrm{SH}$ and $\beta$ g groups. For all parameters, there were no significant changes between the $\mathrm{SH}$ and $\beta \mathrm{g}$ groups. However, $\beta \mathrm{g}$ administration ( $\beta \mathrm{g}$ + I/R group) significantly attenuated the TBARS level and significantly increased the GSH and GPx levels compared with the I/R group. However, $\beta$ g treatment did not significantly improve the CAT and SOD levels. In addition, there was a significant difference between the $\mathrm{SH}$ and $\beta \mathrm{g}+\mathrm{I} / \mathrm{R}$ groups in terms of all parameters except CAT.

\section{Histopathological results}

The cerebral cortices of the mice in the sham group showed a normal cerebral structure and pyramidal cells (Figure 1A, B). The $\beta g$ alone treated group was similar to that of the sham group (Figure 1C, D). However, in the $\mathrm{I} / \mathrm{R}$ group, the cerebral cortices showed morphological damage. Inflammatory cell infiltration (Figure 2A) and congestion (Figure 2B) were seen in this group. In addition, some of the pyramidal cells showed eosinophilic degeneration. The cells appeared contracted and lost their processes with the eosinophilic cytoplasm with small and darkly stained nuclei (Figure $2 \mathrm{C}$ ). In the $\beta \mathrm{g}$ $+\mathrm{I} / \mathrm{R}$ group, although the cerebral tissue preserved its normal histological appearance, mild inflammatory cell infiltration (Figure 3A) and eosinophilic degeneration of the pyramidal cells (Figure 3B) were still marked in some areas.

The results of the histopathological score in all groups were reported in Table II.

\section{DISCUSSION}

Ischemic stroke is a global health problem that causes major complications, such as mortality, morbidity, and long-term disability (Oztanir et al., 2014b; Zhao et al., 2017). For this reason, many experimental models mimicking the ischemic stroke have been developed, and many therapeutic agents, such as $\beta$-myrcene and hesperidin, have been studied in these models (Ciftci, Oztanir, Cetin, 2014; Oztanir et al., 2014a; Sommer, 2017). To our knowledge, the effects of $\beta g$ have not been examined in I/R-induced neuronal damage. In this context, the present study investigated the ameliorating effects of $\beta \mathrm{g}$ in the neuronal damage caused by global cerebral I/R in a C57/BL6 mouse model.

Inflammatory reaction, blood-brain barrier disruption, oxidative stress, and neuronal apoptosis constitute major pathological mechanisms of ischemia-induced brain

TABLE I - The levels of SOD, CAT, GPx, GSH and TBARS in brain tissue of mice

\begin{tabular}{lccccc}
\hline & $\begin{array}{c}\text { TBARS nmol/g } \\
\text { tissue }\end{array}$ & $\begin{array}{c}\text { Reduced GSH } \\
\mathbf{n m o l} / \mathbf{m L}\end{array}$ & $\begin{array}{c}\text { CAT k/mg } \\
\text { protein }\end{array}$ & $\begin{array}{c}\text { SOD U/mg } \\
\text { protein }\end{array}$ & $\begin{array}{c}\text { GPx U/mg } \\
\text { protein }\end{array}$ \\
\hline Sham & $7.21 \pm 0.85^{\mathrm{a}}$ & $243.4 \pm 12.4^{\mathrm{a}}$ & $0.034 \pm 0.001^{\mathrm{a}}$ & $18.34 \pm 1.29^{\mathrm{a}}$ & $198.1 \pm 14.8^{\mathrm{a}}$ \\
$\mathrm{I} / \mathrm{R}$ & $11.9 \pm 0.92^{\mathrm{b}}$ & $184.3 \pm 14.1^{\mathrm{b}}$ & $0.027 \pm 0.002^{\mathrm{b}}$ & $14.60 \pm 2.81^{\mathrm{b}}$ & $154.9 \pm 18.3^{\mathrm{b}}$ \\
Betaglucan & $7.56 \pm 1.02^{\mathrm{a}}$ & $236.9 \pm 10.6^{\mathrm{a}}$ & $0.032 \pm 0.002^{\mathrm{a}}$ & $19.36 \pm 2.06^{\mathrm{a}}$ & $204.9 \pm 14.1^{\mathrm{a}}$ \\
I/R+betaglucan & $9.32 \pm 0.91^{\mathrm{c}}$ & $206.8 \pm 15.2^{\mathrm{c}}$ & $0.030 \pm 0.004^{\mathrm{ab}}$ & $15.23 \pm 1.38^{\mathrm{b}}$ & $173.7 \pm 16.2^{\mathrm{c}}$ \\
\hline
\end{tabular}

Data were presented as mean \pm SD. Means bearing different superscripts within same column were significantly different $(P<0.01)$ 


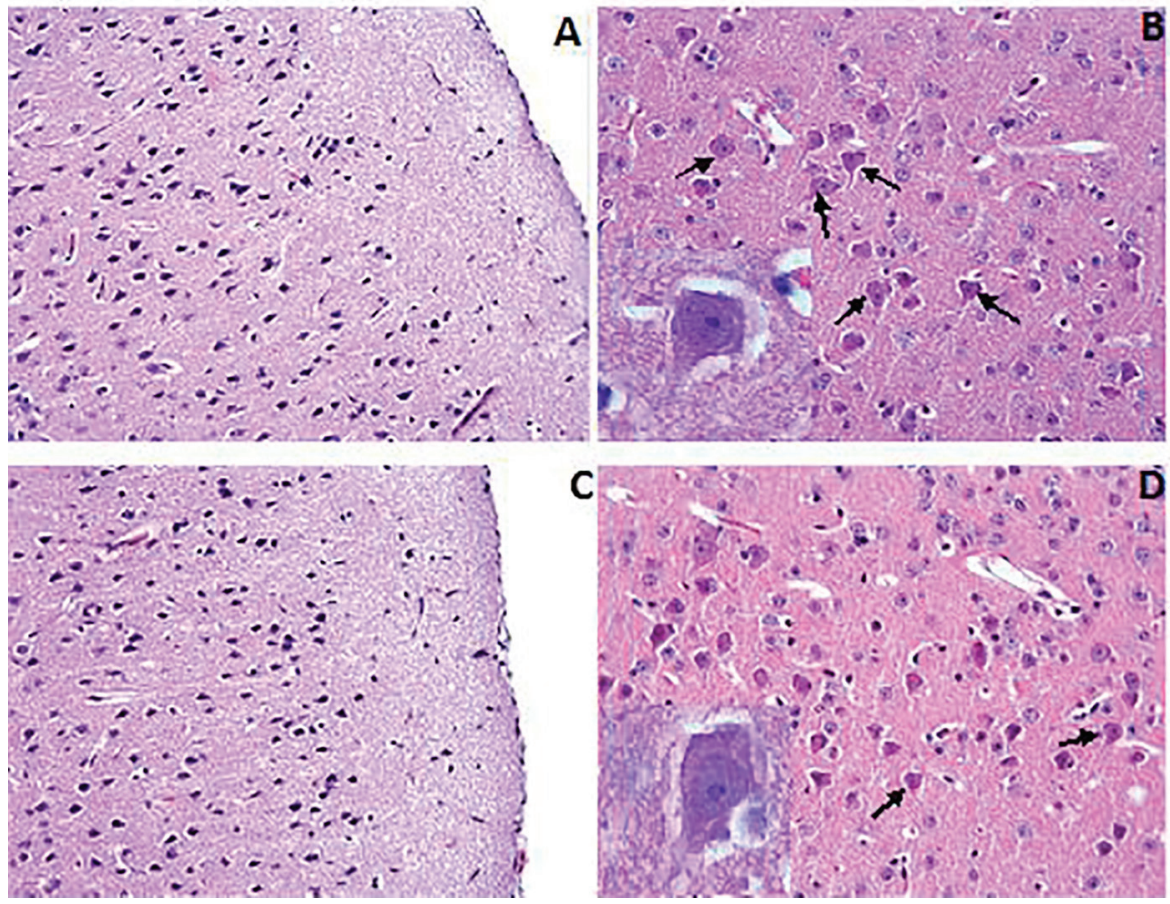

FIGURE 1 - Sham and $\beta$ group showing normal cerebral cortex (A, C) H-E;X20 and pyramidal cell (arrows) (B, D). H-E;X40.
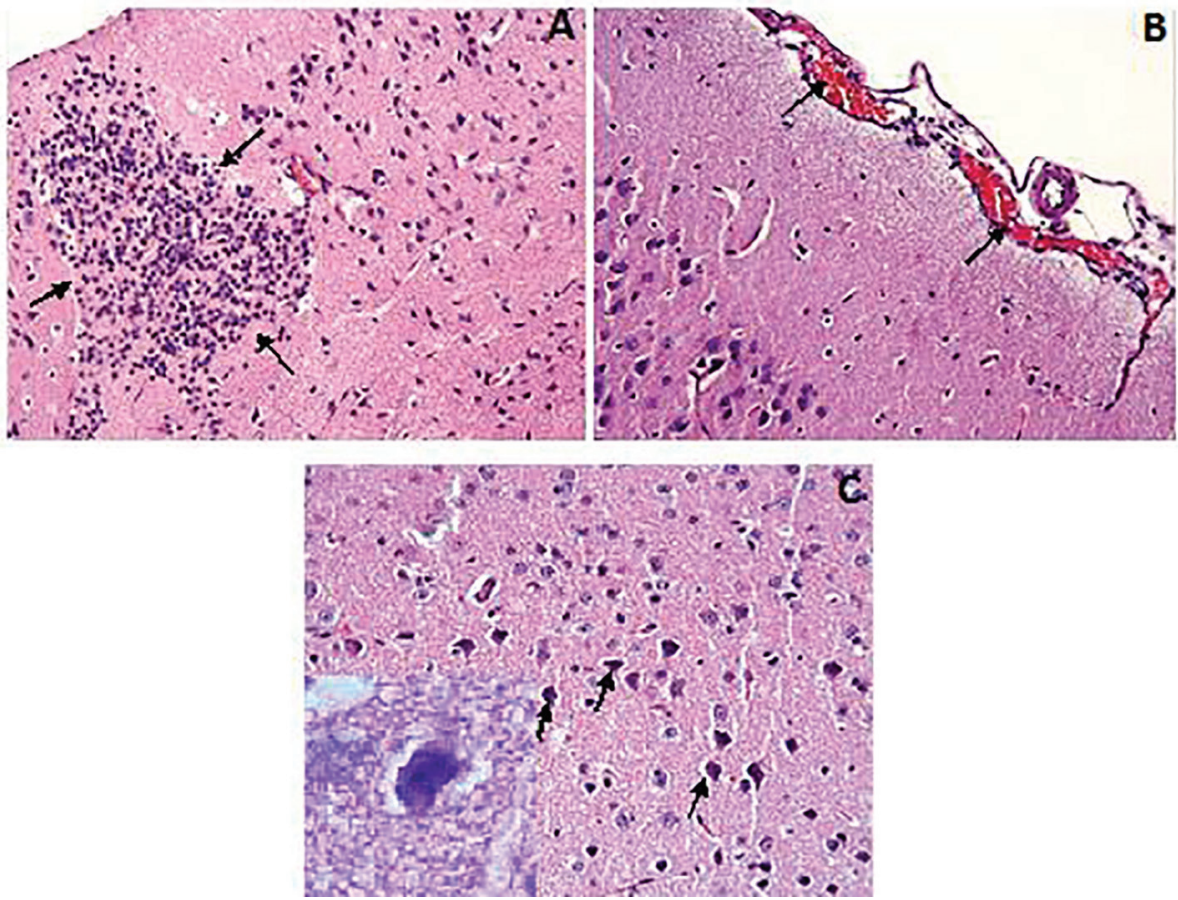

FIGURE 2 - I/R group. (A) notice inflammatuar cell infiltration (arrows) H-E;X20 (B) the appearance of congested blood vessels (arrows) H-E;X40 (C) the view of eosinophilic degeneration of pyramidal cells (arrows) H-E; X40.

damage. Therefore, treatment strategies target these four conditions, and especially antioxidants are successfully used in treatment (Lalkovičová, Danielisová, 2016). Oxidative stress is a cellular imbalance condition between ROS formation and the antioxidant defense system. The restoration of blood flow with reperfusion causes ROS accumulation in the ischemic tissue, and the mechanisms of cell death are triggered (Minutoli et al., 2016). The brain tissue is more susceptible to lipid peroxidation than other tissues. The susceptibility of brain tissue to lipid peroxidation is probably related to its high oxygen demand, low antioxidant capacity, and high methyl ion content 


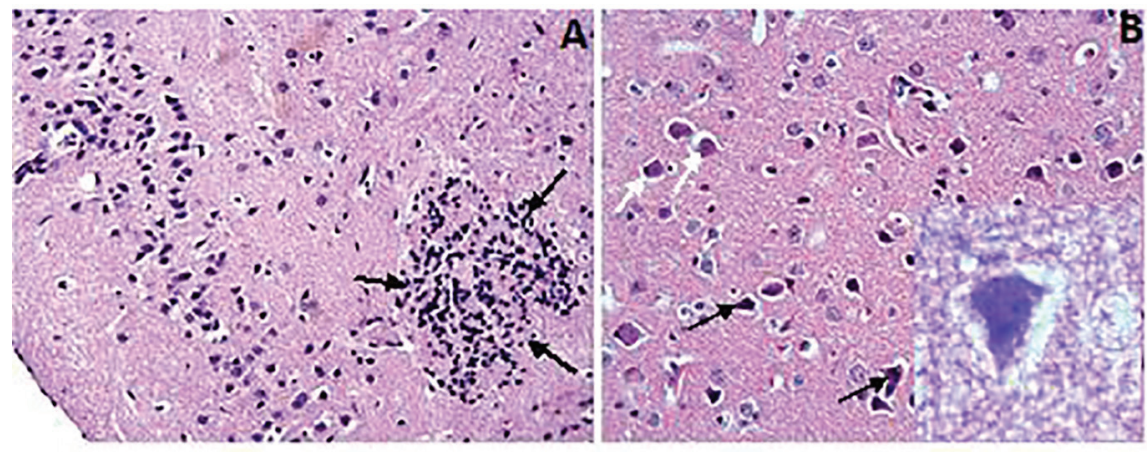

FIGURE 3 - I/R + $\beta$ group (A) the appearance of mild inflammatuar cell infiltration (arrows) H-E;X20 (B) the view of intact pyramidal cells (white arrows) and eosinophilic degeneration of pyramidal cells (black arrows) H-E; X40.

TABLE II - The results of histopathological score in all groups

\begin{tabular}{lc}
\hline Groups & Histopathological score \\
\hline Sham & $0.14 \pm 0.14$ \\
Betaglucan & $0.28 \pm 0.18$ \\
I/R & $1.57 \pm 0.20^{\mathrm{a}}$ \\
I/R+Betaglucan & $0.85 \pm 0.14^{\mathrm{b}}$ \\
\hline
\end{tabular}

Data were presented as mean \pm SEM. ${ }^{\text {aSignificant increase }}$ $(\mathrm{P}<0.05)$, vs. Control group. ${ }^{\mathrm{b}}$ Significant decrease $(\mathrm{P}=0.05)$, vs. I/R group

in some regions of the brain (Lalkovičová, Danielisová, 2016). Therefore, the mechanism of neuroprotection with antioxidants is based on the inhibition of neuronal apoptosis, a reduction in lipid peroxidation, and an increase in the enzymatic and non-enzymatic antioxidant defense systems (Oztanir et al., 2014a).

In the current study, we first evaluated I/R-induced lipid peroxidation by measuring the TBARS level. We observed that global cerebral I/R significantly increased the TBARS level compared with the SH group. Many previous studies about the oxidative status of the brain tissue indicated that I/R caused significant lipid peroxidation (Ciftci, Oztanir, Cetin, 2014; Liang et al., 2015; Oztanir et al., 2014a; Oztanir et al., 2014b; Yu et al., 2016). However, $\beta g$ treatment after $I / R$ caused a significant decrease in the TBARS level. To our knowledge, the present study is the first to report the effects of $\beta \mathrm{g}$ on I/R-induced brain damage. Therefore, we are unable to compare our obtained results with any other work. Nevertheless, the results of some previous studies that have investigated the neuroprotective effects of $\beta \mathrm{g}$ on the brain tissue are consistent with our results. Alp et al. (2012) demonstrated that $\beta$ g significantly ameliorated lipid peroxidation on the brain and sciatic nerve tissues of diabetic rats. In addition, the study of Şener et al. (2005) determined that $\beta \mathrm{g}$ decreased the malondialdehyde level in septic rat brain tissue. In addition, our previous study (Kaya et al., 2016) indicated that $\beta \mathrm{g}$ treatment significantly decreased the TBARS level in cisplatin-damaged brain tissue.

At the same time, in this study, global cerebral I/R caused a significant reduction in the levels of GSH, CAT, SOD, and GPx, which are members of the antioxidant defense system. Similarly, Oztanir et al. (2014b) showed that the GSH, CAT, SOD, and GPx levels were significantly reduced due to experimental global cerebral $\mathrm{I} / \mathrm{R}$ in C57 BL/6J mice. Furthermore, Yu et al. (2016) demonstrated that global cerebral I/R significantly decreases SOD and GPx activity in the four brain regions, including the cortex, hippocampus, hypothalamus, and striatum in rats. Our obtained data were consistent with these results and other similar work results (Ciftci, Oztanir, Cetin, 2014; Oztanir et al., 2014a). However, $\beta$ g treatment after cerebral I/R caused a significant increase in the GSH and GPx levels. The CAT and SOD levels were also increased, without statistical significance. A few previous studies sufficiently demonstrated the booster effects of $\beta g s$ on the neuronal antioxidant defense system. For example, Şener et al. (2005) showed that $\beta \mathrm{g}$ administration significantly ameliorated the GSH level in the brain tissue of septic rats. Our previous study (Kaya et al., 2016) indicated that $50 \mathrm{mg} / \mathrm{kg} /$ day of oral $\beta g$ administration significantly increased the GSH, CAT, SOD, and GPx levels in cisplatin-damaged brain tissue. In addition, it was reported that $\beta \mathrm{g}$ treatment raised both the CAT level and total antioxidant status of the brain and sciatic nerve tissue of diabetic rats (Alp et al., 2012). Furthermore, Kayali et al. (2005) indicated that $\beta g$ did not affect the SOD level in rats with a damaged spinal cord. Moreover, the beneficial antioxidant effects of $\beta g$ on many other organs and tissues outside the nervous system have been extensively demonstrated in past studies. DietrichMuszalska et al. (2011) showed that $1 \mathrm{~h}$ of incubation with $\beta \mathrm{g}$ diminished the haloperidol-induced TBARS 
level by $25 \%$ in human plasma. In addition, Bolcal et al. (2007) indicated that $2 \mathrm{mg} / \mathrm{kg}$ i.p. $\beta g$ treatment significant increased both the GPx and SOD levels in serum and muscle tissue in the limbs of ischemic rabbits. As well, Agostini et al. (2015) demonstrated that $\beta$ g induced the SOD expression in a human vascular endothelial cell culture under an oxidative microenvironment. Our results are consistent with previous studies in general.

In the present study, we also evaluated the histopathological effects of global cerebral I/R in the brain tissue. Global cerebral I/R caused significant structural changes, such as inflammatory cell infiltration and congestion in the brain tissue. In addition, there was eosinophilic degeneration of some pyramidal cells (I/R group). These findings were consistent with the results of previous studies (Liang et al., 2015; Naderi et al., 2017; Oztanir et al., 2014b; Sharifi et al., 2015). For example, Liang et al. (2015) indicated that karyopyknosis caused by I/R decreased the number of neurons and increased the pyknosis ratio. Furthermore, in the study of Yan et al. (2017), it was shown that I/R induced atrophy and edema in both hippocampal and cortical brain cells. Moreover, Öztanır et al. (2014a) demonstrated that I/R created focal ischemic areas, vascular congestion, mononuclear cell infiltration, and the presence of cytoplasmic shrinkage and extensively dark picnotic neuronal nuclei in the brain tissue. On the other hand, the application of $\beta g$ after I/R provided a regression in the histopathological damage largely in our present study ( $\beta g+I / R$ group). We could not find any study that histologically investigated the effects of $\beta \mathrm{g}$ on brain damage caused by $\mathrm{I} / \mathrm{R}$. However, the results of previous studies investigating the effects of $\beta \mathrm{g}$ against many pathological conditions in the nervous or other systems were largely compatible with our results. For example, Selli et al. (2015) showed that $\beta g$ treatment reduced neural degeneration, the number of neurons with hyperchromatic nuclei, and 8-OHdG-positive cell numbers at the cerebral cortex tissue in post-menopausal rats. In addition, Gulmen et al. (2010) showed that $\beta \mathrm{g}$ significantly decreased aortic I/R-induced polymorphonuclear infiltration and intra-alveolar hemorrhage in lung tissue. Furthermore, $\beta \mathrm{g}$ administration caused improvement in histopathological negativities, such as vascular congestion, cell infiltration in the pia mater, and cell infiltration in the cerebral cortex in our previous study (Kaya et al., 2016).

\section{CONCLUSION}

The present study clearly demonstrated that $50 \mathrm{mg} /$ $\mathrm{kg}$ /day of oral $\beta \mathrm{g}$ administration ameliorated the oxidative and histopathological damage caused by global cerebral
$\mathrm{I} / \mathrm{R}$ in $\mathrm{C} 57 \mathrm{BL} / \mathrm{J} 6$ mice. It is likely that this effect is due to the antioxidant and radical scavenging properties of $\beta \mathrm{g}$. For this reason, we claim that $\beta \mathrm{g}$ treatment diminishes global cerebral I/R-induced neuronal damage in the brain.

\section{ACKNOWLEDGEMENT}

This research received no specific grant from any funding agency in the public, commercial, or not-for-profit sectors. The authors declare that they have no conflict of interest.

\section{REFERENCES}

Aebi H, Wyss SR, Scherz B, Skvarıl F. Heterogeneity of Erythrocyte Catalase II. Isolation and characterization of normal and variant erythrocyte catalase and their subunits. Eur J Biochem. 1974;48(1):137-145.

Agostini S, Chiavacci E, Matteucci M, Torelli M, Pitto L, Lionetti V. Barley beta-glucan promotes MnSOD expression and enhances angiogenesis under oxidative microenvironment. J Cell Mol Med. 2014;19(1):227-238.

Alawieh A, Elvington A, Tomlinson S. Complement in the homeostatic and ischemic brain. Front Immunol. 2015;6:417.

Alp H, Varol S, Celik MM, Altas M, Evliyaoglu O, Tokgoz O, Tanriverdi MH, Uzar E. Protective effects of beta glucan and gliclazide on brain tissue and sciatic nerve of diabetic rats induced by streptozosin. Exp Diabetes Res. 2012;2012:230342.

Bolcal C, Yildirim V, Doganci S, Sargin M, Aydin A, Eken A, Ozal E, Kuralay E, Demirkiliç U, Tatar H. Protective effects of antioxidant medications on limb ischemia reperfusion injury. J Surg Res. 2007;139(2):274-279.

Ciftci O, Oztanir MN, Cetin A. Neuroprotective effects of $\beta$-Myrcene following global cerebral ischemia/reperfusionmediated oxidative and neuronal damage in a C57BL/J6 mouse. Neurochem Res. 2014;39(9):1717-1723.

Dietrich-Muszalska A, Olas B, Kontek B, Rabe-Jabłońska J. Beta-glucan from Saccharomyces cerevisiae reduces plasma lipid peroxidation induced by haloperidol. Int J Biol Macromol. 2011;49(1):113-116.

Gulmen S, Kiris I, Kocyigit A, Kumbul Dogus D, Ceylan BG, Meteoglu I. $\beta$-Glucan protects against lung injury induced by abdominal aortic ischemia-reperfusion in rats. J Surg Res. 2010;164(2):325-332. 
Kaya K, Ciftci O, Cetin A, Tecellioğlu M, Başak N. Beneficial effects of $\beta$-glucan against cisplatin side effects on the nervous system in rats. Acta Bras Cir. 2016;31(3):198-205.

Kayali H, Ozdag MF, Kahraman S, Aydin A, Gonul E, Sayal A, Odabasi Z, Timurkaynak E. The antioxidant effect of betaGlucan on oxidative stress status in experimental spinal cord injury in rats. Neurosurg Rev. 2005;28(4):298-302.

Lalkovičová M, Danielisová V. Neuroprotection and antioxidants. Neural Regen Res. 2016;11(6):865-874.

Liang G, Shi B, Luo W, Yang J. The protective effect of caffeic acid on global cerebral ischemia-reperfusion injury in rats. Behav Brain Funct. 2015 Apr 18;11:18.

Minutoli L, Puzzolo D, Rinaldi M, Irrera N, Marini H, Arcoraci $\mathrm{V}$, et al. ROS-Mediated NLRP3 inflammasome activation in brain, heart, kidney, and testis ischemia/reperfusion injury. Oxid Med Cell Longev. 2016(8):1-10.

Naderi Y, Sabetkasaei M, Parvardeh S, Zanjani TM. Neuroprotective effect of minocycline on cognitive impairments induced by transient cerebral ischemia/reperfusion through its anti-inflammatory and anti-oxidant properties in male rat. Brain Res Bull. 2017;131:207-213.

Oztanir MN, Ciftci O, Cetin A, Aladag MA. Hesperidin attenuates oxidative and neuronal damage caused by global cerebral ischemia/reperfusion in a C57BL/J6 mouse model. Neurol Sci. 2014a;35(9):1393-1399.

Oztanir MN, Ciftci O, Cetin A, Durak MA, Basak N, Akyuva Y. The beneficial effects of $18 \beta$-glycyrrhetinic acid following oxidative and neuronal damage in brain tissue caused by global cerebral ischemia/reperfusion in a C57BL/J6 mouse model. Neurol Sci. 2014b;35(8):1221-1228.

Paglia DE, Valentine WN. Studies on the quantitative and qualitative characterization of erythrocyte glutathione peroxidase. J Lab Clin Med. 1967;70(1):158-169.

Park SM, Park CW, Lee TK, Cho JH, Park JH, Lee JC, et al. Effect of ischemic preconditioning on antioxidant status in the gerbil hippocampal CA1 region after transient forebrain ischemia. Neural Regen Res. 2016;11(7):1081-1089.

Sedlak J, Lindsay RH. Estimation of total, protein-bound, and nonprotein sulfhydryl groups in tissue with Ellman's reagent. Anal Biochem.1968;25(1):192-205.
Selli J, Unal D, Mercantepe F, Akaras N, Kabayel R, Unal B, Atilay $\mathrm{H}$. Protective effects of beta glucan in brain tissues of post-menopausal rats: a histochemical and ultra-structural study. Gynecol Endocrinol. 2016;32(3):234-239.

Sharifi ZN, Movassaghi S, Mohamadzadeh F, Asl SS, Pourheydar B, Mehdizadeh M. Reduction in ischemic brain injury following the administration of pentoxifylline after transient global ischemia / reperfusion in a rat model. Med J Islam Repub Iran. 2015;29:193.

Sommer CJ. Ischemic stroke : experimental models and reality. Acta Neuropathol. 2017;133(2):245-261.

Sun K, Fan J, Han J. Ameliorating effects of traditional Chinese medicine preparation, Chinese materia medica and active compounds on ischemia/reperfusion-induced cerebral microcirculatory disturbances and neuron damage. Acta Pharm Sin B. 2015;5(1):8-24

Sun Y, Oberley LW, Li Y. A simple method for clinical assay of superoxide dismutase. Clin Chem.1988;34(3):497-500.

Şener G, Toklu H, Ercan F, Erkanli G. Protective effect of $\beta$-glucan against oxidative organ injury in a rat model of sepsis. Int Immunopharmacol. 2005;5(9):1387-1396.

Yagi K. Simple assay for the level of total lipid peroxides in serum or plasma. Methods Mol Biol. 1998;108:101-106.

Yan X, Li H, Bai M, Miao M. Effect of total flavonoids of Radix Ilicis Pubescentis on cerebral ischemia reperfusion model. Saudi J Biol Sci. 2017;24(3):595-602

Yonekura I, Kawahara N, Nakatomi H, Furuya K, Kirino T. A model of global cerebral ischemia in C57 BL/6 mice. J Cereb Blood Flow Metab. 2004;24(2):151-158.

Yu B, Ruan M, Zhang ZN, Cheng HB, Shen XC. Synergic effect of borneol and ligustrazine on the neuroprotection in global cerebral ischemia/reperfusion injury: a region-specificity study. Evid Based Complement Alternat Med. 2016;2016:4072809.

Zhao Z, Lu Z, Sun X, Zhao T, Zhang J, Zhou C, Zheng X, Zhang $\mathrm{H}$, Shi G. Global transcriptomic profiling of cortex and striatum: cerebral injury after ischemia/reperfusion in a mouse model. J Stroke Cerebrovasc Dis. 2017;26(7):1622-1632.

Received for publication on $02^{\text {nd }}$ May 2018 Accepted for publication on $21^{\text {st }}$ June 2018 